The University of Southern Mississippi The Aquila Digital Community

Faculty Publications

$10-1-2007$

\title{
Abusive Supervision, Upward Maintenance Communication, and Subordinates' Psychological Distress
}

\author{
Bennett J. Tepper \\ Georgia State University \\ Sherry E. Moss \\ Wake Forest University \\ Daniel E. Lockhart \\ University of Kentucky \\ Jon C. Carr \\ University of Southern Mississippi
}

Follow this and additional works at: http://aquila.usm.edu/fac_pubs

Part of the Business Commons

\section{Recommended Citation}

Tepper, B. J., Moss, S. E., Lockhart, D. E., Carr, J. C. (2007). Abusive Supervision, Upward Maintenance Communication, and Subordinates' Psychological Distress. Academy of Management Journal, 50(5), 1169-1180.

Available at: http://aquila.usm.edu/fac_pubs/1899 


\title{
ABUSIVE SUPERVISION, UPWARD MAINTENANCE COMMUNICATION, AND SUBORDINATES' PSYCHOLOGICAL DISTRESS
}

\author{
BENNETT J. TEPPER \\ Georgia State University \\ SHERRY E. MOSS \\ Wake Forest University \\ DANIEL E. LOCKHART \\ University of Kentucky \\ JON C. CARR \\ University of Southern Mississippi
}

\begin{abstract}
This study reanalyzes data from Tepper's (2000) two-wave study regarding the effects of subordinates' perceptions of supervisory abuse to assess previously unexamined relationships. As predicted, we found that subordinates who more rather than less strongly perceived that they had been abused by supervisors tended to use regulative maintenance tactics with higher frequency. Further, the positive relationship between abusive supervision and subordinates' psychological distress was exacerbated by subordinates' use of regulative maintenance communications, and that relationship was reduced by subordinates' use of direct maintenance communication. Theoretical and practical implications are discussed.
\end{abstract}

In recent years, management researchers have investigated abusive supervision, subordinates' perceptions of supervisors' sustained displays of hostile verbal and nonverbal behaviors (Tepper, 2000: 178). ${ }^{1}$ Abusive supervision in the form of ridiculing, undermining, and yelling at subordinates is a source of chronic stress that produces serious negative consequences (Tepper, 2007). Like victims of domestic abuse (Emery \& LaumannBillings, 1998), victims of abusive supervision experience heightened psychological distress (Duffy, Ganster, \& Pagon, 2002), indications of strain that involve dysfunctional thoughts and emotions (e.g., anxiety, depression, and emotional exhaustion).

This research was supported by a Summer Research Grant awarded to the first author by Georgia State University's Robinson College of Business. An earlier version of this paper was presented at the 2005 Annual Meeting of the Southern Management Association, where it won the Best Overall Paper Award. We thank Debra Shapiro and two anonymous reviewers for the many helpful recommendations they gave us during the process of revising our work.

${ }^{1}$ In keeping with extant theory and research, we use the term "abusive supervision" to refer to perceived abuse perpetrated by supervisors against those who directly report to them.
Investigations of how employees respond to abusive supervision suggest that subordinates perceiving more rather than less of it engage in more retaliation and revenge behavior (Aquino, Tripp, \& Bies, 2001; Bies \& Tripp, 2001; Duffy et al., 2002; Inness, Barling, \& Turner, 2005). However, people rarely retaliate against higher-status abusers (Kim, Smith, \& Brigham, 1998). As Ashforth (1994) noted, retaliatory responses sustain the hostile behaviorial pattern of abusive supervisors and can produce relational deterioration. For subordinates who depend on their supervisor for valued resources (e.g., promotions, raises, and continued employment), engaging in behaviors designed to maintain a functional working relationship is a more practical communication strategy than engaging in retaliatiory behaviors with the potential to aggravate or terminate the relationship.

Accordingly, we explore subordinates' use of upward maintenance communication under circumstances of abusive supervision. Upward maintenance communication consists of behaviors designed to maintain relationships with supervisors around a baseline level of intimacy and attachment (Lee, 1998). These behaviors can be distinguished from relationship improvement communication (behaviors that signal the desire for a deeper level of reciprocated 
intimacy and that are used to enrich or mend relationships [Wilmot, 1979]) and relationship dissolution communication (behaviors that are used to terminate relationships [Emmers \& Canary, 1996]). Subordinates' upward maintenance communication includes regulative tactics-attempts to maintain relationships by avoiding contact and censoring and distorting messages (e.g., talking superficially, avoiding asking for direction, and stretching the truth to avoid problems) - and direct tactics: efforts to maintain relationships by communicating relational expectations, questioning relational injustices, and openly discussing relationship problems with supervisors (Waldron, 1991). ${ }^{2}$

Our research contributes to the management literature in two ways. First, our study is the first to explore relationships between abusive supervision and upward maintenance communication. Only three studies have investigated subordinates' use of upward maintenance communication and, in each study, the researchers focused on the quality of leader-member exchange, the extent to which supervisorsubordinate relationships are characterized by trust, mutual respect, and an exchange of valued resources (e.g., Waldron, 1991; Waldron \& Hunt, 1992; Waldron, Hunt, \& Dsilva, 1993). Given the conceptual and empirical distinctions between leader-member exchange and abusive supervision-low-quality leader-member exchanges do not necessarily involve hierarchical abuse, and abusive supervision explains incremental variance in psychological distress above and beyond that explained by leader-member exchange (Harris, Kacmar, \& Boonthanum, 2005)—our research represents a new direction in management theory and research.

Second, our study is the first to investigate the role that upward maintenance communication plays in determining the level of psychological distress reported by subordinates perceiving abusive supervision. Regulative and direct maintenance tactics respectively capture content that converges with the two major classes of coping behavior that have been investigated in previous research: avoidant coping (attempts to focus attention away from sources of stress or from the strain reactions associated with exposure to stressors) and ap-

\footnotetext{
${ }^{2}$ People may use behavior akin to regulative tactics and direct tactics to improve or dissolve relationships. Our conceptual analysis therefore focuses exclusively on subordinates' use of regulative and direct tactics for the purpose of maintaining relationships with supervisors, and we use data collected in accordance with the maintenance communication research paradigm to ensure fidelity between our conceptual work and construct measurement.
}

proach coping (efforts to directly confront sources of stress [Carver, Scheier, \& Weintraub, 1989]). We invoke coping theory and research to develop predictions as to how subordinates' use of upward maintenance communication influences the positive relationship between abusive supervision and psychological distress. Our work thus reexamines the roles that coping behaviors (such as maintenance communication) play in the relationship between perceived exposure to work stressors and psychological distress.

Our research is important from a practical standpoint because the health consequences of abusive supervision are costly. Psychological distress in the form of emotional exhaustion is associated with decreased productivity and higher turnover (Wright \& Cropanzano, 1998), and the annual cost of employees' depression to U.S. organizations has been estimated at $\$ 50$ billion for medical treatment (Durso, 2004 ) and $\$ 44$ billion for absence and reduced performance (Stewart, Ricci, Chee, Hahn, \& Morgenstein, 2003). Hence, to the extent that the use of maintenance communication has implications for subordinates' psychological distress associated with abusive supervision, our research addresses issues that are of importance to management practice.

\section{THEORETICAL BACKGROUND}

\section{Abusive Supervision and Subordinates' Upward Maintenance Communication}

Most maintenance communication research has focused on the maintenance of relationships from which individuals derive satisfaction (Dindia \& $\mathrm{Ca}$ nary, 1993), but individuals are also motivated to maintain undesirable relationships that are instrumental in achieving desired outcomes (Wilmot, 1979). An inevitable feature of social life is involvement in unwanted relationships with disliked people, relationships that individuals have little choice but to endure and maintain (Hess, 2002). People may have unwanted relationships with family members or others in their social environment (e.g., roommates, schoolmates, fellow club members, or neighbors). Unwanted relationships also occur at work, one example being relationships with abusive supervisors.

People maintain unwanted relationships by creating psychological or physical distance between themselves and disliked partners (Hess, 2000), a strategy that dovetails with regulative maintenance tactics. The notion of distancing has its roots in the rich literature that addresses avoidance behavior: action that provides escape from noxious stimuli before they are presented (Rachlin, 1976). It has 
been shown that in work settings, individuals engage in avoidance behaviors to alleviate the discomfort associated with threatening people and situations (e.g., Folger \& Skarlicki, 1998). Similarly, then, the avoidant nature of regulative maintenance tactics ought to be attractive to subordinates who perceive their supervisors to be abusive. Thus, we predict:

Hypothesis 1. Abusive supervision is positively related to subordinates' use of regulative maintenance tactics.

On the face of it, the use of direct tactics would also appear to be an efficacious way of maintaining relationships, and subordinates might be expected to use direct tactics frequently. However, research in the areas of "issue selling" and "organizational silence" suggest that employees are generally unwilling to speak out (e.g., protest injustice, "whistle-blow," report performance deficits, or voice unpopular opinions) unless they think that doing so will be effective and not too personally costly (Dutton, Ashford, Lawrence, \& Miner-Rubino, 2002; Morrison \& Milliken, 2000). The use of direct tactics requires trust (subjective belief that another party will protect one's interests [Mayer, Davis, \& Schoorman, 1995]); subordinates will feel that it is safe to air perceived injustices if they feel they can count on their supervisor to treat the information as constructive feedback. In situations of abusive supervision, subordinates typically feel low levels of trust (Bies \& Tripp, 1996) and, as a result, should view direct maintenance tactics as a particularly risky form of communication. Under some circumstances, communication akin to direct tactics may be viewed as antagonistic. For example, Brett, Shapiro, and Lytle identified a communication strategy they labeled "rights" involving "references to norms, standards, fairness, justice, or contractual issues" (1998: 415). Such communication falls within the broader domain of contentious communication when rights-oriented messages are essentially used to indicate that a wrongful act needs correction. This study focused on the communication behavior of parties to a simulated dispute who had equal power (rather than unequal power derived from an enduring hierarchical relationship), but the study's findings supported the idea that the use of direct maintenance tactics may be interpreted as an aggressive form of communication. This possibility, coupled with the tendency for subordinates to avoid expressing perceived injustice when doing so seems costly, leads us to believe that subordinates will exercise greater caution about using direct tactics when they perceive their supervisors to be prone to hostility. Thus, we predict:

Hypothesis 2. Abusive supervision is negatively related to subordinates' use of direct maintenance tactics.

\section{Upward Maintenance Communication and Subordinates' Psychological Distress}

Consistently with the characterization of abusive supervision as among chronic work stressors (longterm threats to well-being, such as ongoing unemployment, persistent financial worries, and relationship problems), the results of several studies suggest that abusive supervision is positively related to subordinates' psychological distress (Duffy et al., 2002; Harris et al., 2005; Tepper, 2000). We expected that the strength of this relationship would vary with subordinates' use of maintenance communication because avoidant coping (which is embodied in regulative maintenance communication) and approach coping (which is embodied in direct maintenance communication) have different effects on the relationship between exposure to chronic stressors and psychological distress. Avoidant behaviors are maladaptive responses to chronic stressors because they interfere with more appropriate action and can evoke new and more severe sources of stress (Holohan, Moos, Holohan, Brennan, \& Schutte, 2005). Avoiding a hostile supervisor using regulative maintenance tactics may (1) engender role ambiguity if restricting contact with the supervisor causes the subordinate to lose access to needed information and resources, (2) interfere with the subordinate's productivity to the extent he or she invests time and effort in avoidance rather than in productive work behaviors, and (3) reinforce the image of the subordinate as a vulnerable target for further victimization (Tepper, Duffy, Henle, \& Lambert, 2006).

It is reasonable to ask why subordinates perceiving abusive supervision use regulative maintenance tactics frequently if doing so is maladaptive. One explanation for this phenomenon comes from temporal motivation theory, which suggests that short-term consequences are more powerful motivators than long-term consequences and that people are motivated to perform behaviors that are immediately reinforced even when the long-term consequences are aversive (Steel \& Konig, 2006). The use of regulative maintenance tactics may be reinforced (negatively) in the short term because this practice is associated with the immediate avoidance of exposure to abuse, which produces favorable emotional states. In addition, those who 
use regulative maintenance tactics may not be aware their behavior is producing long-term damage to their well-being; many psychologically distressed people are unaware that they are not well (Simon, 1998). Hence, in situations involving abusive supervision, the positive consequences of using regulative maintenance tactics (getting distance from perpetrators) are easier to recognize and more immediate than are the negative consequences (psychological distress). This line of reasoning supports our contention that although abusive supervision is positively related to subordinates' use of regulative maintenance communication (as spelled out in Hypothesis 1), the use of regulative maintenance tactics exacerbates the positive relationship between abusive supervision and subordinates' psychological distress.

Hypothesis 3. The positive relationship between abusive supervision and subordinates' psychological distress is stronger when subordinates' use of regulative maintenance tactics is higher.

Approach strategies buffer the effects of chronic stressors because they give individuals under stress an opportunity to directly confront and master those threats (Jex, Bliese, Buzzell, \& Primeau, 2001; Roth \& Cohen, 1986) and better manage the negative emotions stressful experiences engender (Gross, 1998; Gross \& John, 2003). Hence, to the extent that direct maintenance tactics share features of approach coping, the use of direct tactics can be expected to diminish the positive relationship between abusive supervision and subordinates' psychological distress.

Hypothesis 4. The positive relationship between abusive supervision and subordinates' psychological distress is weaker when subordinates' use of direct maintenance tactics is higher.

\section{METHODS}

\section{Sample and Procedures}

We tested the hypotheses using data supplied by Tepper (2000), who surveyed supervised employees at two points in time separated by six months. At time 1, Tepper (2000) used random digit dialing to precall 2,415 residents of a midwestern city. Of those called, 1,073 were not eligible for the study either because they were not employed or because they did not have supervisors at work. Of the 1,342 who were eligible, 1,064 agreed to participate, 741 of whom returned completed survey questionnaires via business reply envelopes. Eliminating surveys with missing data $(n=29)$ produced a time 1 sample size of 712 and a usable response rate of 53 percent (712 completed surveys/1,342 eligible people contacted). At time 2, those who had returned surveys at time 1 were phoned and invited to complete follow-up surveys. Four hundred seventy-five individuals could be located, still had the same supervisors, and were willing to participate. Three hundred forty-two returned completed surveys by business reply envelopes (see Tepper [2000] for further description of the sample). ${ }^{3}$

\section{Measures}

Abusive supervision. Tepper's (2000) time 1 survey included a 15-item measure of abusive supervision. Respondents used a five-point scale ranging from 1, "I cannot remember him/her ever using this behavior with me," to 5 , "He/she uses this behavior very often with me," to report the frequency with which their boss used behaviors such as "tells me my thoughts and feelings are stupid" and "makes negative comments about me to others."

Upward maintenance communication. Tepper's (2000) time 2 survey contained Waldron's (1991) five-item measures of subordinates' use of direct and regulative maintenance communication. In keeping with the maintenance communication paradigm, we prefaced this section of the survey with a description of the differences among communication tactics designed to improve, dissolve, or maintain relationships. The items were then introduced as "things that people might do to maintain their relationships with their supervisors," and respondents were instructed to report whether "you have been behaving this way toward your supervisor in the last six months." Respondents used a sevenpoint scale ranging from 1, "very strongly disagree," to 7 , "very strongly agree," and illustrative items are, "spoke up when I felt he/she treated me unjustly" (direct) and "talked only superficially with him/her" (regulative).

Psychological distress. Tepper's (2000) time 2 survey also included three measures of psycholog-

\footnotetext{
${ }^{3}$ The four hypotheses introduced here have not been tested in previous research. The same data set has been used to investigate the relationship between abusive supervision and subordinates' psychological distress (Tepper, 2000) and between abusive supervision and subordinates' resistance behavior (Tepper, Duffy, \& Shaw, 2001). Confirmatory factor analysis results suggest no overlap between the measures of subordinates' resistance, which were the focus of Tepper et al.'s (2001) study, and the measures of upward maintenance communication, which were the focus of the current research.
} 
ical distress: the six-item anxiety scale from the Diagnostic Interview Schedule (Robins, 1986), the Center for Epidemiologic Studies' six-item depression scale (Radloff, 1977), and the six-item emotional exhaustion scale from the Maslach Burnout Inventory (Maslach \& Jackson, 1986). Respondents used a four-point scale ranging from 0 , "never," to 3, "often," to report how often in the previous few months they had experienced symptoms that were consistent with the content domains for anxiety ("felt afraid for no reason"), depression ("wondered if anything is worthwhile"), and emotional exhaustion ("felt burned out from your work").

Control variables. The time 1 survey contained measures of several variables that previous research using the same data set has linked with the outcomes of abusive supervision (e.g., Tepper, 2000; Tepper et al., 2001) and that warranted being controlled for in our analyses: subordinates' neuroticism, agreeableness, conscientiousness, perceived job mobility, distributive justice, procedural justice, and interactional justice. Neuroticism, the trait tendency to experience negative emotional states, has been linked with the coping strategies people use and the level of psychological distress they experience (Bolger, 1995; Shewchuk, Elliott, MacNeir-Semands, \& Harkins, 1999). Compared to people who are low in agreeableness, people who are high in agreeableness behave in a manner that reflects concern for relational issues (Barrett \& Pietromonaco, 1997), and they may therefore be more strongly motivated to use both forms of maintenance communication with supervisors. Conscientious people, who tend to be concerned with task accomplishment (Costa \& McCrae, 1992), may eschew regulative maintenance tactics, which may, as we noted earlier, interfere with subordinates' productivity. Job mobility (the perception that one has attractive employment alternatives) affords workers a sense of personal control, a psychological state that has been linked with coping responses and strain reactions (Frazier, Mortensen, \& Steward, 2005; Perrewe \& Ganster, 1989). We also controlled for subordinates' senses of distributive justice (employees' perceptions that they have received fair outcomes), procedural justice (their perceptions that decision makers have used fair procedures while rendering allocation decisions), and interactional justice (employees' perceptions that they have been treated fairly on an interpersonal basis). We controlled for these three types of fairness perceptions because they have been linked with the outcomes of abusive supervision, including psychological well-being (Tepper, 2000).

Neuroticism, agreeableness, and conscientiousness were assessed with Costa and McCrae's (1992) 12-item measures. Example items are, "I am not a worrier" (neuroticism, reverse-scored); "I try to perform all the tasks assigned to me conscientiously" (conscientiousness); and "If necessary, I am willing to manipulate people to get what I want" (agreeableness, reverse-scored). Perceived job mobility was measured with the following 2 items: "If I were to quit my job, I could find another one that is just as good" and "I would have no problem finding an acceptable job if I quit." Illustrative justice items are, "I am fairly rewarded considering my responsibilities" (distributive justice, 5 items); "My employer makes decisions in an unbiased manner" (procedural justice, 5 items); and "My boss treats me fairly" (interactional justice, 2 items). The response format for all control variables ranged from 1 , "strongly disagree," to 5 "strongly agree."

\section{RESULTS}

We assessed responses to the survey items using maximum likelihood confirmatory factor analysis. The fit of a 13-factor model $\left(\chi^{2}[4,109]=7,361.87\right)$ was superior to the fit of a 12-factor model in which the direct maintenance and regulative maintenance items were specified as loading on the same factor $\left(\Delta \chi^{2}[12]=416.75, p<.01\right)$ and an 11-factor model in which the anxiety, depression, and emotional exhaustion items loaded on the same factor $\left(\Delta^{2}[23]\right.$ $=480.86, p<.01$ ). In addition, the 13-factor model's root-mean-square error of approximation (.05) and comparative fit index (.94) were acceptable, and all factor loadings were significant $(p<.01)$. We therefore treated the items as measures of the constructs they were designed to measure by averaging the appropriate item scores to form total scores for abusive supervision $(\alpha=.91)$, neuroticism $(\alpha=.84)$, agreeableness $(\alpha=.70)$, conscientiousness $(\alpha=.76)$, distributive justice $(\alpha=.95)$, procedural justice $(\alpha=.88)$, interactional justice $(\alpha=.88)$, job mobility $(\alpha=.78)$, direct tactics ( $\alpha=$ $.84)$, regulative tactics $(\alpha=.74)$, anxiety $(\alpha=.88)$, depression $(\alpha=.87)$, and emotional exhaustion $(\alpha=.89)$.

Table 1 shows descriptive statistics for the study variables. Supporting Hypotheses 1 and 2, abusive supervision was positively related to subordinates' use of regulative tactics and negatively related to subordinates' use of direct tactics, respectively. We performed more rigorous tests of these predictions by regressing respondents' maintenance tactic scores on the control variables (step 1) and abusive supervision (step 2). The regression results, shown in Table 2, indicate that at step 2, abusive supervision was positively related to subordinates' use of regulative maintenance tactics $\left(\Delta R^{2}=.02, b=.14\right.$, 
TABLE 1

Descriptive Statistics and Correlations ${ }^{a}$

\begin{tabular}{|c|c|c|c|c|c|c|c|c|c|c|c|c|c|c|c|}
\hline Variable & Mean & s.d. & $\mathbf{1}$ & 2 & 3 & 4 & 5 & 6 & 7 & 8 & $\mathbf{9}$ & 10 & 11 & 12 & 13 \\
\hline $\begin{array}{l}\text { 1. Abusive } \\
\text { supervision }\end{array}$ & 1.42 & 0.57 & $(.91)$ & & & & & & & & & & & & \\
\hline 2. Neuroticism & 2.37 & 0.64 & $.18^{* *}$ & $(.84)$ & & & & & & & & & & & \\
\hline 3. Agreeableness & 3.89 & 0.45 & $-.18^{\star *}$ & $-.24 * *$ & $(.70)$ & & & & & & & & & & \\
\hline 4. Conscientiousness & 4.07 & 0.47 & -.05 & $-.40 * *$ & $.14^{* *}$ & $(.76)$ & & & & & & & & & \\
\hline $\begin{array}{l}\text { 5. Distributive } \\
\text { justice }\end{array}$ & 3.09 & 1.10 & $-.37^{\star *}$ & $-.12^{\star}$ & $.12^{*}$ & .00 & $(.95)$ & & & & & & & & \\
\hline 6. Procedural justice & 3.06 & 0.97 & $-.50 * *$ & $-.15^{* *}$ & $.14 * *$ & .04 & $.57 * *$ & $(.88)$ & & & & & & & \\
\hline $\begin{array}{l}\text { 7. Interactional } \\
\text { justice }\end{array}$ & 3.75 & 1.11 & $-.62^{* *}$ & $-.11^{*}$ & $.16^{* *}$ & -.02 & $.34^{* *}$ & $.52 * *$ & $(.88)$ & & & & & & \\
\hline 8. Job mobility & 3.18 & 1.18 & .01 & -.09 & .03 & $.14^{* *}$ & -.03 & .06 & -.01 & $(.77)$ & & & & & \\
\hline 9. Direct tactics & 4.75 & 1.27 & $-.17^{* *}$ & .02 & $.12^{*}$ & .01 & .11 & .24 ** & $.34^{\star *}$ & .02 & $(.83)$ & & & & \\
\hline 10. Regulative tactics & 3.40 & 1.20 & $.24 * *$ & $.15^{* *}$ & -.03 & $-.16^{\star *}$ & $-.14^{* *}$ & $-.24 * *$ & $-.32 * *$ & -.03 & -.05 & $(.75)$ & & & \\
\hline 11. Anxiety & 0.92 & 0.71 & $.25^{* *}$ & $.33^{* *}$ & $-.23^{* *}$ & -.10 & $-.20^{* *}$ & $-.20 * *$ & $-.19^{* *}$ & -.10 & $-.14^{*}$ & $.18^{* *}$ & $(.88)$ & & \\
\hline 12. Depression & 1.31 & 0.72 & $.23^{* *}$ & $.41^{* *}$ & $-.26^{* *}$ & $-.17^{* *}$ & -.22 ** & $-.25^{* *}$ & $-.21 * *$ & $-.14^{* *}$ & $-.12^{*}$ & $.21^{* *}$ & .80 ** & $(.87)$ & \\
\hline $\begin{array}{l}\text { 13. Emotional } \\
\text { exhaustion }\end{array}$ & 1.35 & 0.80 & $.38^{* *}$ & $.30^{* *}$ & $-.30^{* *}$ & -.06 & $-.36^{* *}$ & $-.37^{* *}$ & $-.38^{* *}$ & -.02 & $-.17^{* *}$ & $.25^{* *}$ & $.67^{* *}$ & $.67 * *$ & $(.89)$ \\
\hline
\end{tabular}

${ }^{\text {a }} n=342$. Alpha internal consistency reliability coefficients appear on the main diagonal in parentheses.

${ }^{*} p<.05$

$* * p<.01$

TABLE 2

Regression Results for Subordinates' Use of Upward Maintenance Tactics ${ }^{\mathbf{a}}$

\begin{tabular}{|c|c|c|c|c|}
\hline \multirow[b]{2}{*}{ Predictors } & \multicolumn{2}{|c|}{$\begin{array}{l}\text { Regulative } \\
\text { Tactics }\end{array}$} & \multicolumn{2}{|c|}{ Direct Tactics } \\
\hline & Step 1 & Step 2 & Step 1 & Step 2 \\
\hline Neuroticism & .06 & .06 & $.10^{+}$ & .09 \\
\hline Agreeableness & .06 & .06 & .08 & .08 \\
\hline Conscientiousness & $-.15^{\star \star}$ & $-.15^{* *}$ & .04 & .04 \\
\hline Distributive justice & .00 & .00 & -.06 & -.05 \\
\hline Procedural justice & -.08 & -.08 & $.11^{\dagger}$ & $.13^{*}$ \\
\hline Interactional justice & $-.29^{\star *}$ & $-.28^{* *}$ & $.30^{* *}$ & $.34^{* *}$ \\
\hline Job mobility & .00 & .00 & .02 & .01 \\
\hline Abusive supervision & & $.14^{*}$ & & -.09 \\
\hline$F$ & 8.04 & 7.03 & 7.44 & 6.74 \\
\hline$\Delta R^{2}$ & $.14^{* *}$ & $.02^{*}$ & $.14^{* *}$ & .01 \\
\hline Total $R^{2}$ & $.14^{\star *}$ & $.16^{* *}$ & $.14^{\star *}$ & $.15^{* *}$ \\
\hline $\begin{aligned} &{ }^{\mathrm{a}} n=342 . \mathrm{Tab} \\
& \text { weights. } \\
&{ }^{+} p<.10 \\
&{ }^{*} p<.05 \\
&{ }^{* *} p<.01\end{aligned}$ & value & are sta & dized $\mathrm{I}$ & gression \\
\hline
\end{tabular}

$p<.05$ ) but unrelated to subordinates' use of direct maintenance tactics $\left(\Delta R^{2}=.01, b=-.09\right.$, n.s.). Hence, Hypothesis 1 was supported, but Hypothesis 2 was not supported.

We tested Hypotheses 3 and 4 by regressing respondents' psychological distress scores on the control variables (step 1), the main effects of abu- sive supervision, regulative tactics, and direct tactics (step 2), and interaction terms consisting of the abusive supervision times regulative tactics and abusive supervision times direct tactics cross-products (step 3). Prior to forming the interaction terms, we centered all predictors. The regression results, which are presented in Table 3, show that the interaction terms explained significant $(p<.01)$ incremental variance in anxiety $(5 \%)$, depression $(4 \%)$, and emotional exhaustion (3\%). Examination of the beta weights associated with the interaction terms suggested that the abusive supervision times regulative tactics cross-product explained significant variance in depression and emotional exhaustion and approached significance for anxiety $(p<$ .10 ) and that the abusive supervision times direct tactics interaction explained significant variance in anxiety, depression, and emotional exhaustion.

Plots of the significant interaction effects using the procedures outlined by Cohen and Cohen (1983) confirmed our hypotheses that the use of regulative tactics exacerbates the relationship between abusive supervision and subordinates' psychological distress (Hypothesis 3) and that the use of direct maintenance tactics reduces the relationship between abusive supervision and subordinates' psychological distress (Hypothesis 4). Because the interactions took similar forms for the various measures of psychological distress, we present two illustrative figures. The plot of the effect of the abusive supervision times regulative tactics interaction on emotional exhaustion, shown in 
TABLE 3

Results of Regression Analyses for Subordinates' Psychological Distress ${ }^{\text {a }}$

\begin{tabular}{|c|c|c|c|c|c|c|c|c|c|}
\hline \multirow[b]{2}{*}{ Predictors } & \multicolumn{3}{|c|}{ Anxiety } & \multicolumn{3}{|c|}{ Depression } & \multicolumn{3}{|c|}{ Emotional Exhaustion } \\
\hline & Step 1 & Step 2 & Step 3 & Step 1 & Step 2 & Step 3 & Step 1 & Step 2 & Step 3 \\
\hline Neuroticism & $.28 * *$ & $.27 * *$ & $.30 * *$ & $.33^{* *}$ & $.33^{* *}$ & $.35 * *$ & $.21 * *$ & $.21 * *$ & $.22 * *$ \\
\hline Agreeableness & $-.14^{*}$ & $-.13^{\star}$ & $-.13^{\star}$ & $-.15^{\star \star}$ & $-.15^{\star *}$ & $-.15^{\star *}$ & $-.19 * *$ & $-.18 * *$ & $-.19 * *$ \\
\hline Conscientiousness & .04 & .07 & .05 & .00 & .02 & .01 & .05 & .07 & .07 \\
\hline Job mobility & -.08 & -.08 & -.08 & $-.11 *$ & $-.10^{*}$ & $-.10^{*}$ & -.01 & -.01 & -.01 \\
\hline Distributive justice & $-.10^{+}$ & -.10 & -.08 & -.10 & $-.10^{+}$ & -.08 & $-.19 * *$ & $-.18 * *$ & $-.18 * *$ \\
\hline Procedural justice & -.03 & .01 & -.03 & -.07 & -.05 & -.07 & $-.10^{\star}$ & -.06 & $-.09 *$ \\
\hline Interactional justice & -.09 & .04 & .01 & -.08 & -.01 & -.03 & $-.21 * *$ & $-.11^{*}$ & $-.12^{*}$ \\
\hline Abusive supervision & & $.13^{\star}$ & .02 & & .04 & .04 & & $.11^{*}$ & .03 \\
\hline Regulative tactics & & $.11^{*}$ & $.08^{*}$ & & $.12^{*}$ & $.09^{*}$ & & $.12^{*}$ & $.11^{*}$ \\
\hline Direct tactics & & $-.10^{*}$ & -.06 & & $-.08^{+}$ & -.04 & & -.06 & -.03 \\
\hline Abusive supervision $\times$ regulative tactics & & & $.08^{+}$ & & & $.07 *$ & & & $.12^{*}$ \\
\hline Abusive supervision $\times$ direct tactics & & & $-.22 * *$ & & & $-.17 * *$ & & & $-.09 *$ \\
\hline$F$ & 9.82 & 9.05 & 10.21 & 15.62 & 11.77 & 11.68 & 20.64 & 15.73 & 14.61 \\
\hline$\Delta R^{2}$ & $.17 * *$ & $.03 * *$ & $.05 * *$ & $.25 * *$ & $.01 *$ & $.04 * *$ & $.30 * *$ & $.02 * \star$ & $.03 * *$ \\
\hline Total $R^{2}$ & $.17 * *$ & $.20 * *$ & $.25 * *$ & $.25 * *$ & $.26 * \star$ & $.30 * *$ & $.30 * *$ & $.32 * *$ & $.35^{\star *}$ \\
\hline
\end{tabular}

${ }^{\mathrm{a}} n=342$. Tabled values are standardized regression weights.

$+p<.10$

${ }^{*} p<.05$

$\star * p<.01$

Figure 1, indicates that the relationship between abusive supervision and emotional exhaustion was stronger when subordinates' use of regulative maintenance tactics was higher $(b=.18, p<.01)$ rather than lower $(b=-.05$, n.s.). This pattern, which is consistent with Hypothesis 3, also emerged for the interactions between abusive supervision and regulative tactics on anxiety and on depression. The plot of effect of the abusive supervision times direct tactics interaction, shown in Figure 2, indicates that the relationship between abusive supervision and emotional exhaustion was weaker when subordinates' use of direct maintenance tactics was higher $(b=-.10$, n.s. $)$ rather than lower $(b=.19, p<.01)$. This pattern, which is consistent with Hypothesis 4, also emerged for the interactions between abusive supervision and direct tactics on anxiety and on depression.

\section{DISCUSSION}

Our discussion focuses on our study's contributions to the management literature and identifies the study's limitations, directions for future research, and practical implications.

\section{Contributions to Management Theory and Research}

Our research contributes to the management literature in several ways. First, our study extends the
FIGURE 1

Effects of Interaction between Abusive Supervision and Regulative Maintenance Tactics on Subordinates' Emotional Exhaustion

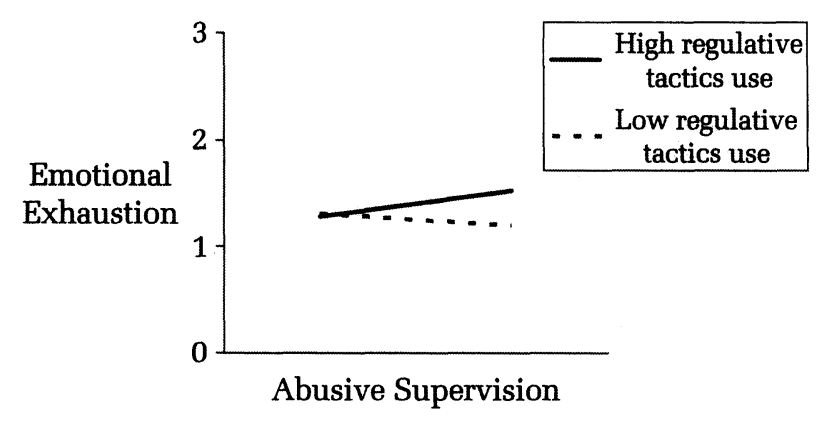

FIGURE 2

Interaction between Abusive Supervision and Direct Maintenance Tactics on Subordinates' Emotional Exhaustion

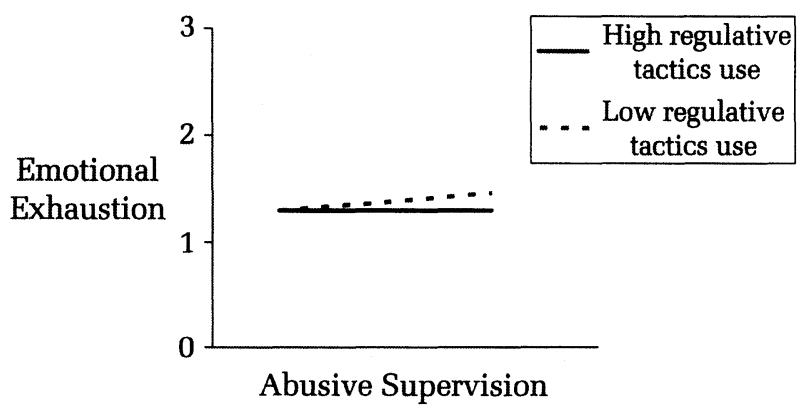


work of Waldron and colleagues (Waldron, 1991; Waldron \& Hunt, 1992; Waldron et al., 1993), which did not explore subordinates' use of maintenance communications when they perceived themselves to be victims of abusive supervision. In so doing, we extend abusive supervision research, which has emphasized the potential that abusive supervisory behavior has to evoke negative reciprocity, retaliation, and revenge behavior (e.g., Aquino et al., 2001; Duffy et al., 2002; Inness et al., 2005). Our work broadens this research stream in accordance with previous research demonstrating that in ongoing supervisor-subordinate relationships, most upward communication is maintenance-oriented (Waldron, 2002). Although we recognize the importance of continuing to investigate subordinates' retaliatory and aggressive responses to abusive supervision, to capture the full picture of what goes on in abusive relationships, management theory and research should incorporate relationship maintenance processes.

Second, our research extends the work that has uncovered a positive relationship between abusive supervision and subordinates' psychological distress (e.g., Tepper, 2000) by showing that the strength of this relationship depends on the ways subordinates use maintenance communication. We must acknowledge that our findings suggest that maintenance communication does not have implications for well-being outside of unwanted relationships-for subordinates who perceived their supervisors to be less abusive, psychological distress levels were generally low, regardless of the ways they used maintenance communication (see Figures 1 and 2). However, an important implication of our findings is that subordinates perceiving abusive supervision face a coping dilemma because, compared to subordinates who report less abuse, they are more likely to use maintenance communication that exacerbates the effects of abusive supervision. Hence, management theory and research should reflect the notion that subordinates in situations of abusive supervision tend to be attracted to maintenance communications that are associated with greater psychological distress (i.e., regulative tactics).

Third, our research contributes to theory and research suggesting that there can be value in "speaking up" in organizational contexts, via means such as issue selling (Dutton et al., 2002), whistle-blowing (Gundlach, Douglas, \& Martinko, 2003; Near \& Miceli, 1995), error reporting (Zhao \& Olivera, 2006), and resolving employee disputes (Brett, Shapiro, \& Lytle, 1998). At a minimum, our work demonstrates that failing to speak up-that is, eschewing direct maintenance tactics or employing regulative maintenance tactics-may be associated with psychological distress. Additionally, our findings suggest that the latter distress will be greater for subordinates who perceive more rather than less abusive supervision. Although the contexts referenced above differ from exposure to abusive supervision, the decision to not speak up may have psychological health consequences similar to those reported here and should be investigated in future research.

The absence of support for one of our predictions warrants some discussion. Although abusive supervision correlated negatively with subordinates' use of direct tactics (see Table 1), this relationship became nonsignificant in the presence of the control variables (see Table 2). Further examination of Tables 1 and 2 reveals a pattern of findings that is consistent with the notion that the zero-order relationship between abusive supervision and subordinates' direct maintenance tactics was mediated or explained by two of the control variables, subordinates' procedural justice and interactional justice. Specifically, abusive supervision was negatively related to subordinates' procedural justice and interactional justice; procedural justice and interactional justice explained variance in direct tactics; and the relationship between abusive supervision and direct tactics became nonsignificant in the presence of procedural justice and interactional justice (Baron \& Kenny, 1986). One explanation for this pattern of results is based on the notion that people use justice information to make inferences about the trustworthiness of higher authorities. According to fairness heuristic theory, people who have received fair (unfair) treatment believe that decision makers can (cannot) be counted on to operate in their best interests (van den Bos, Wilke, \& Lind, 1998). The measures of procedural justice and interactional justice may have captured the level of trust subordinates had in their supervisors, a psychological state that should be associated with subordinates' willingness to use direct maintenance tactics. This explanation must be regarded as speculative, however, because Tepper's (2000) data did not contain a measure of relational trust that we could use to test these ideas more directly.

\section{Limitations and Directions for Future Research}

Several limitations of our study can be noted to help guide future research. One limitation is that all data were collected from the same source. On the positive side, common method bias can be largely (though not completely) ruled out as an explanation for the results given that (1) a multifactor model provided better fit to the covariance ma- 
trix than a one-factor model (Podsakoff, MacKenzie, Lee, \& Podsakoff, 2003), (2) we obtained interactions that followed the hypothesized form (Evans, 1985), and (3) the hypotheses were supported in a sample in which the key predictor, abusive supervision, and the criteria (maintenance communication and psychological distress) were separated by six months (Podsakoff et al., 2003). Still, constructive replication using multiparty research designs would bolster confidence in the findings reported here.

A second limitation is that Tepper (2000) used a four-point response format for the measures of psychological distress, including the emotional exhaustion items from the Maslach Burnout Inventory, which ordinarily employs a seven-point response format. This modification does not appear to have created measurement problems that diminished the power of our hypothesis tests, because the results for emotional exhaustion were as expected and consistent with the findings for the other measures of psychological distress. Still, modifications of this sort limit the extent to which researchers can integrate findings over studies, and it would be worthwhile to replicate our research using the response format that has been used in previous studies using the Maslach Burnout Inventory.

A third set of limitations has to do with the availability of relevant control and criterion variables. As we noted above, Tepper's (2000) data set did not include a measure of relational trust, which may be a proximal explanation of subordinates' use of direct maintenance tactics. On the other hand, we did control for variables such as interactional justice that have been highly positively associated with trust and other relational perceptions. In addition, the data set did not allow us to control for the extent to which subordinates are competent at using direct tactics; it may be argued that employees differ in the extents to which they use direct maintenance tactics effectively, particularly when dealing with abusive supervisors. Future research should therefore investigate the predictions tested here after controlling for subordinates' communication competence. As for criterion variables, we were not able to explore outcomes that may explain why subordinates who perceive abusive supervision find regulative maintenance communication attractive. Regulative maintenance communication is attractive presumably because, in situations of abusive supervision, such tactics afford short-term relief, an immediate sense of comfort that our measures of psychological distress do not capture (Steel \& Konig, 2006). Future research should explore the short-term effects of regulative and direct mainte- nance communication using outcome variables such as daily mood and research designs such as diary studies or behavior sampling.

A final limitation is that our analysis relied on Waldron's (1991) maintenance tactic framework, which was not designed to focus on unwanted relationships per se. Waldron's direct tactics (which capture references to hierarchical mistreatment) and regulative tactics (which converge with the distancing tactics that Hess [2000] investigated in studies of maintenance communication in nonwork relationships) appear to be relevant to relationships with supervisors who seem abusive. Still, it would be fruitful to conduct further, exploratory research aimed at identifying whether subordinates who perceive abuse use qualitatively different maintenance behaviors than those that Waldron (1991) identified. We also note that people may use communication akin to regulative tactics and direct tactics to improve or dissolve relationships and that the maintenance communication paradigm does not rule out the possibility that respondents reported having used these tactics for purposes other than maintaining the relationship with their supervisors; for example, people may use communication akin to regulative maintenance tactics to terminate relationships, and they may use communication akin to direct maintenance tactics to improve relationships. That said, our measures likely captured the content that was intended because most communication between dyadic partners involves maintenance communication rather than relationship improvement communication or relationship dissolution communication (Wilmot, 1979).

\section{Implications for Practice}

In reviewing the practical implications of our work, we focus on prescriptions for both employeevictims of abusive supervision and for employers. Our research suggests that subordinates who perceive supervisory abuse need a tiered set of responses. Such subordinates should try to use direct maintenance tactics initially. If direct maintenance tactics are ineffective (that is, relationships deteriorate or subordinates' psychological distress increases), these subordinates should make every effort to secure alternative employment and to use regulative maintenance tactics, but only on a shortterm basis.

Addressing abusive supervision from a managerial perspective is also complicated. To the extent that subordinates are unwilling to speak up about the injustices they have experienced (i.e., are unwilling to use direct maintenance tactics), abusive 
supervision may easily go undetected and unmanaged, producing unnecessary and costly psychological distress. Unable to depend on subordinates under these circumstances to use effective communication strategies or to report experiences of abuse, management may have to rely on well-constructed surveys to detect occurrences of abusive supervision. Assessing abusive supervision by means of department-coded surveys would protect the anonymity of individual respondents while facilitating identification of perpetrators. Managers whose employees report seriously low levels of psychological health that are determined to be abuse-related should be a source of immediate concern to top and human resources managers, who must be prepared to take unequivocal action that sends a clear message that abusive supervision will not be tolerated (e.g., instituting zero-tolerance policies). Hopefully, the findings of this study linking abusive supervision to the psychological distress of employees who perceive such abuse will help managers recognize the importance of preventing such experiences in the workplace. Hopefully, too, the moderating relationship involving upward maintenance communication reported here will help guide managers as well as management scholars in determining what actions (by employees and/or managers) may help mitigate the negative health consequences of abusive supervision.

\section{REFERENCES}

Aquino, K., Tripp, T. M., \& Bies, R. J. 2001. How employees respond to personal offense: The effects of blame attribution, victim status, and offender status on revenge and reconciliation in the workplace. Journal of Applied Psychology, 86: 52-59.

Ashforth, B. 1994. Petty tyranny in organizations. Human Relations, 47: 755-778.

Baron, R. M., \& Kenny, D. A. 1986. The moderator-mediator distinction in social psychological research: Conceptual, strategic, and statistical considerations. Journal of Personality and Social Psychology, 51: 1173-1182.

Barrett, L. F., \& Pietromonaco, P. R. 1997. Accuracy of the five-factor model in predicting perceptions of daily social interactions. Personality and Social Psychology Bulletin, 23: 1173-1188.

Bies, R. J., \& Tripp, T. M. 1996. Beyond distrust: Getting even and the need for revenge. In R. M. Kramer \& T. R. Tyler (Eds.), Trust in organizations: Frontiers of theory and research: 246-260. Thousand Oaks, CA: Sage.

Bies, R. J., \& Tripp, T. M. 2001. A passion for justice: The rationality and morality of revenge. In R. Cropan- zano (Ed.), Justice in the workplace: From theory to practice: 197-208. Mahwah, NJ: Erlbaum.

Bolger, N. 1995. A framework for studying personality in the stress process. Journal of Personality and Social Psychology, 69: 890-902.

Brett, J. M., Shapiro, D. L., \& Lytle, A. L. 1998. Breaking the bonds of reciprocity in negotiations. Academy of Management Journal, 41: 410-424.

Carver, C. S., Scheier, M. F., \& Weintraub, J. K. 1989. Assessing coping strategies: A theoretically based approach. Journal of Personality and Social Psychology, 56: 267-283.

Cohen, J., \& Cohen, P. 1983. Applied multiple regression/correlation analysis for the behavioral sciences. Hillsdale, NJ: Erlbaum.

Costa, P. T., \& McCrae, R. R. 1992. The NEO PI/FFI manual supplement. Odessa, FL: Psychological Assessment Resources.

Dindia, K., \& Canary, D. J. 1993. Definitions and theoretical perspectives on maintaining relationships. Journal of Social and Personal Relationships, 10: 163173.

Duffy, M. K., Ganster, D. C., \& Pagon, M. 2002. Social undermining at work. Academy of Management Journal, 45: 331-351.

Durso, K. A. 2004. Depression in the workplace: Prevalence, cost, and productivity impact. Medical Benefits, 22(December): 6-7.

Dutton, J. E., Ashford, S. J., Lawrence, K. A., \& MinerRubino, K. 2002. Red light, green light: Making sense of the organizational context for issue selling. Organization Science, 13: 355-369.

Emery, R. E., \& Laumann-Billings, L. 1998. An overview of the nature, causes, and consequences of abusive family relationships: Toward differentiating maltreatment and violence. American Psychologist, 53: 121-135.

Emmers, T. M., \& Canary, D. J. 1996. The effect of uncertainty reduction strategies on young couples' relational repair and intimacy. Communication Quarterly, 44: 16-182.

Evans, M. G. 1985. A Monte Carlo study of the effects of correlated method variance in moderated regression analysis. Organizational Behavior and Human Decision Processes, 36: 305-323.

Folger, R., \& Skarlicki, D. P. 1998. When tough times make tough bosses: Managerial distancing as a function of layoff blame. Academy of Management Journal, 41: 79-87.

Frazier, P. A., Mortensen, H., \& Steward, J. 2005. Coping strategies as mediators of the relations among perceived control and distress in sexual assault survivors. Journal of Counseling Psychology, 52: 267278.

Gross, J. J. 1998. Antecedent and response-focused emo- 
tion regulation: Divergent consequences for experience, expression, and physiology. Journal of Personality and Social Psychology, 74: 224-237.

Gross, J. J., \& John, O. P. 2003. Individual differences in two emotion regulation processes: Implications for affect, relationships, and well-being. Journal of Personality and Social Psychology, 85: 348-362.

Gundlach, M. J., Douglas, S. C., \& Martinko, M. J. 2003. The decision to blow the whistle: A social information processing framework. Academy of Management Review, 28: 107-123.

Harris, K. J., Kacmar, K. M., \& Boonthanum, R. 2005. The interrelationship between abusive supervision, leader-member exchange, and various outcomes. Paper presented at the Annual Meeting of the Society for Industrial and Organizational Psychology, Los Angeles.

Hess, J. A. 2000. Maintaining involuntary relationships with disliked partners: An investigation into the use of distancing behaviors. Human Communication Research, 26: 458-488.

Hess, J. A. 2002. Maintaining unwanted relationships. In D. J. Canary \& M. Dainton (Eds.), Maintaining relationships through communication: Relational, contextual, and cultural variations: 103-124. Mahwah, NJ: Erlbaum.

Holohan, C. J., Moos, R. H., Holahan, C. K., Brennan, P. L., \& Schutte, K. K. 2005. Stress generation, avoidance coping, and depressive symptoms: A 10-year model. Journal of Consulting and Clinical Psychology, 73: 658-666.

Inness, M., Barling, J., \& Turner, N. 2005. Understanding supervisor-targeted aggression: A within-person, between-jobs design. Journal of Applied Psychology, 90: 731-739.

Jex, S. M., Bliese, P. D., Buzzell, S., \& Primeau, J. 2001. The impact of self-efficacy on stressor-strain relations: Coping style as an explanatory mechanism. Journal of Applied Psychology, 86: 401-409.

Kim, S. H., Smith, R. H., \& Brigham, N. L. 1998. The effects of power imbalance and the presence of third parties on upward and downward revenge. Personality and Social Psychology Bulletin, 24: 353-361.

Lee, J. 1998. Maintenance communication in superior-subordinate work relationships: An exploratory investigation of group social context and the "Pelz effect." Southern Communication Journal, 63: 144-159.

Maslach, C., \& Jackson, S. E. 1986. Maslach burnout inventory (2nd ed.). Palo Alto, CA: Consulting Psychologists Press.

Mayer, R. C., Davis, J. H., \& Schoorman, F. D. 1995. An integrative model of organizational trust. Academy of Management Review, 20: 709-734.

McCrae, R. R. 1990. Controlling for neuroticism in the measurement of stress. Stress Medicine, 6: 237-241.

Morrison, E. W., \& Milliken, F. J. 2000. Organizational silence: A barrier to change and development in a pluralistic world. Academy of Management Review, 25: 706-731.

Near, J. P., \& Miceli, M. P. 1996. Whistle-blowing: Myth and reality. Journal of Management, 22: 507-527.

Perrewe, P. L., \& Ganster, D. C. 1989. The impact of job demands and behavioral control on experienced job stress. Journal of Organizational Behavior, 10: 213-229.

Podsakoff, P. M., MacKenzie, S. B., Lee, J. Y., \& Podsakoff, N. P. 2003. Common method biases in behavioral research: A critical review of the literature and recommended remedies. Journal of Applied Psychology, 88: 879-903.

Rachlin, H. 1976. Behavior and learning. San Francisco: Freeman.

Radloff, L. 1979. The CES-D scale: A self-report measure depression scale for research in the general population. Applied Psychological Measurement, 1: 385-401.

Robins, L. 1986. The development and characteristics of the NIMH Diagnostic Interview Schedule. In M. Weissman, J. Myers, \& C. Ross (Eds.), Community surveys of psychiatric disorders: 403-407. New Brunswick, NJ: Rutgers University Press.

Roth, S., \& Cohen, L. J. 1986. Approach, avoidance, and coping with stress. American Psychologist, 7: 813819.

Shewchuck, R. M., Elliot, T. R., MacNair-Semands, R. R., \& Harkins, S. 1999. Trait influences on stress appraisal and coping: An evaluation of alternative frameworks. Journal of Applied Social Psychology, 29: 685-704.

Simon, G. E. 1998. Can depression be managed appropriately in primary care? Journal of Clinical Psychiatry, 59(2): 3-8.

Steel, P., \& Konig, C. J. 2006. Integrating theories of motivation. Academy of Management Review, 31: 889-913.

Stewart, W. F., Ricci, J. A., Chee, E., Hahn, S. R., \& Morgenstein, D. 2003. Cost of lost productive work time among U.S. workers with depression. Journal of the American Medical Association, 289: 3135-3145.

Tepper, B. J. 2000. Consequences of abusive supervision. Academy of Management Journal, 43: 178-190.

Tepper, B. J. 2007. Abusive supervision in work organizations: Review, synthesis, and research agenda. Journal of Management, 33: 261-289.

Tepper, B. J., Duffy, M. K., Henle, C. A., \& Lambert, L. S. 2006. Procedural injustice, victim precipitation, and abusive supervision. Personnel Psychology, 59: 101123.

Tepper, B. J., Duffy, M. K., \& Shaw, J. D. 2001. personality moderators of the relationship between abusive supervision and subordinates' resistance. Journal of Applied Psychology, 86: 974-983. 
van den Bos, K., Wilke, H. A. M., \& Lind, E. A. 1998. When do we need procedural fairness? The role of trust in authority. Journal of Personality and Social Psychology, 75: 1449-1458.

Waldron, V. R. 1991. Achieving communication goals in superior-subordinate relationships: The multi-functionality of upward maintenance tactics. Communication Monographs, 58: 289-306.

Waldron, V. R. 2002. Relationship maintenance in organizational settings. In D. J. Canary \& M. Dainton (Eds.), Maintaining relationships through communication: Relational, contextual, and cultural variations: 163-184. Hillsdale, NJ: Erlbaum.

Waldron, V. R., \& Hunt, M. 1992. Hierarchical level and quality of supervisory relationship as predictors of subordinates' use of maintenance tactics. Communication Reports, 5: 82-89.

Waldron, V. R., Hunt, M. \& Dsilva, M. 1993. Towards a threat management model of upward communication: A study of influence and maintenance tactics in the leader-member dyad. Communication Studies, 44: 254-272.

Wilmot, W. W. 1979. Dyadic communication (2nd ed.). Menlo Park, CA: Addison-Wesley.

Wright, T. A., \& Cropanzano, R. 1998. Emotional exhaustion as a predictor of job performance and voluntary turnover. Journal of Applied Psychology, 83: 486493.

Zhao, B., \& Olivera, F. 2006. Error reporting in organizations. Academy of Management Review, 31: 1012-1030.

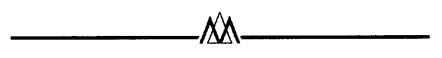

Bennett J. Tepper (btepper@gsu.edu) is a professor of managerial sciences in the J. Mack Robinson College of Business at Georgia State University. He received his Ph.D. in organizational psychology from the University of Miami. His current research interests include leadership, behavioral ethics, and psychological health.

Sherry E. Moss (sherry.mossmba@wfu.edu) is an associate professor of organizational behavior in the Babcock Graduate School of Management at Wake Forest University. She earned her Ph.D. in organizational behavior and theory at Florida State University. Her research focuses on causal attributions, feedback giving, feedback seeking, and other interpersonal processes that occur within the context of the supervisor-subordinate dyad.

Daniel E. Lockhart (bad316@uky.edu) is an assistant professor of management in the Gatton College of Business at the University of Kentucky. He received his Ph.D. in strategic management from the University of Kentucky. His research interests include corporate governance, boards of directors, and abusive supervision.

Jon C. Carr (jon.car@usm.edu) is an associate professor of management in the College of Business at the University of Southern Mississippi. He received his Ph.D. in management from Mississippi State University. His current research interests include attitudinal and behavioral topics as they relate to organizational behavior, entrepreneurship, and family business. 